\title{
REFLEXIONES ACERCA DE LOS SISTEMAS DE INFORMACION UNIVERSITARIOS ANTE LOS DESAFIOS Y CAMBIOS GENERADOS POR LOS PROCESOS DE EVALUACION Y ACREDITACION
}

\author{
SANTIAGo José BARCos*
}

Recebido em: 28/07/07

Aprovado: 20/01/2008

\begin{abstract}
* Licenciado Santiago José Barcos, Profesor Titular de Administración I y de Administración de la Educación y de las Instituciones Educativas en las Facultades de Ciencias Económicas y de Humanidades y Ciencias de la Educación, respectivamente, de la Universidad Nacional de La Plata, junio de 2007.

sjbarcos@econo.unlp.edu.ar; ac-sirft@ec.gba.gov.ar
\end{abstract}

Resumen: Este artículo trata de la relevancia de los Sistemas de Información para universidades. Tales sistemas son esenciales para la gestión, para lograr enriquecer los resultados de la adopción de decisión y también para informar las acciones de las universidades a la sociedad. El artículo contiene algunas reflexiones respecto de los Sistemas de Informaciones en los Procesos de Evaluación y Acreditación y muestra los defectos detectados en Universidades Europeas y Latinoamericanas. Asimismo, se plantean requerimientos y funciones de este importante recurso y un especial énfasis en desarrollarlos adecuadamente para optimizar el funcionamiento y para impulsar la integración entre Instituciones Educativas en el contexto global.

Palavras-chave: Sistemas de Información . Universidad-Evaluación. Acreditación-Integración.

\author{
SOME REFLEXIONS ABOUT INFORMATIONS SYSTEMS FOR \\ UNIVERSITIES IN THE PRESENCE OF CHALLENGES AND \\ CHANGES PRODUCED BY EVALUATION AND ACREDITATION PROCESSES
}

\begin{abstract}
This article explains about the relevance that the Informations Systems have for universities, which are essential for management, to rich decision-making results, and also to report their actions to society. It contains some reflections about the necessity of Informations Systems in the Evaluation and Accreditation Processes, and expresses the faults detected in European and Latin American universities. Lastly, there is an enunciation of requirements and functions of this important resource, and a special emphasis on developing them properly to improve the integration between the Education Institutions in the global context.
\end{abstract}

Key words: Informations Systems. University-Evaluation. Acreditation-Integration.

Estamos viviendo la tercera revolución en cuanto al acceso al conocimiento y los nuevos contextos y desafíos para la educación y las universidades, con renovados criterios de pertinencia académica y de las competencias requeridas, con procesos de formación continua y permanente y con nuevos mecanismos de integración sociedad-conocimiento. La necesidad de políticas consensuadas de conocimiento y de una gestión universitaria autónoma, pertinente, eficiente y responsable revaloriza a la información. (Conferencia de N. Fernández Lamarra, UNLP, jun. 2006) 
Los líderes, administradores y dirigentes de la antigüedad y de distintas culturas tanto europeas como americanas; incluso precolombinas, que, obviamente, no poseían los medios actuales reconocían el valor de la información y la imposibilidad de adoptar decisiones sin información confiable, comprensible y oportuna. (BARCOS, S.J. La administración antes del siglo XX-UNLP, 2006)

Si bien todas las organizaciones siempre han contado con alguna forma de sistema para registrar, procesar, almacenar, recuperar y presentar información sobre sus operaciones y actividades, hasta no hace mucho lo hacían casi exclusivamente para fines presupuestarios o estadísticos. Durante mucho tiempo, la idea de que la información es más que el mero mantenimiento de registros parecía extraño a la mayoría de las personas no así a los directivos ni a los administradores responsables. Desde la década del sesenta y con mas énfasis en los últimos 20 años, todas las organizaciones y en todos sus niveles han advertido que la información es un activo sumamente valioso. La calidad de las instancias de decisión a nivel directivo, de las cuales depende su éxito, está directamente relacionada con la calidad de la información con la que se cuenta. En el ámbito educativo, se confirman estas aseveraciones.

Para ser útiles, los sistemas de información en educación deben proporcionar una amplia gama de datos. En toda la estructura, la mayor necesidad sigue siendo la creación, implementación y funcionamiento eficaz de sistemas de información que permitan contar con datos orientados al alumnado, a los docentes, investigadores y extensionistas y a la administración y gestión para la solución de diversos problemas y para evaluar el efecto de las acciones educativas internas y sobre la sociedad. Esta idea ha venido forzando gradualmente a las organizaciones a percibir los sistemas de información de manera diferente, mas como herramienta de apoyo a las decisiones que como un simple registro de datos históricos. Como se señala en diversos documentos de comercialización de hardware y software, los sistemas de información están saliendo gradualmente del "cuarto de atrás" al que habían sido relegados y pasando a las salas de interacción directa de los niveles ejecutivos.

La información y la tecnología utilizada para apoyar su adquisición, procesamiento, almacenamiento, recuperación y difusión han adquirido importancia estratégica en todo tipo de organizaciones y también en las educativas de todos los niveles del sistema, sean públicas o privadas y tanto si planifican, coordinan 
y evalúan como si ejecutan acciones educativas en forma directa, dejando de ser elementos que sólo tenían que ver con apoyo operativo y administrativo o que servían para cumplir con lo estipulado en un reglamento, norma o programa.

Todos los que trabajamos en educación sabemos que la información es esencial para decidir; constituye un recurso clave y un requisito previo para el suministro eficaz y la gestión de los servicios. El mejor acceso a la misma se reconoce como un ingrediente de suma utilidad para los servicios educativos y para la planificación, diagnóstico, funcionamiento y supervisión de planes y programas; además, contribuye a la evaluación de las actividades educativas y de los resultados de la intervención académica y de gestión.

Importantes experiencias han demostrado los adelantos que se pueden lograr, en materia de eficiencia, eficacia, efectividad y relevancia, con la utilización de sistemas de recolección y procesamiento de datos que se hayan elaborado en forma adecuada y establecido con propiedad. También, existe consenso en las dificultades que aún no se han salvado para producir información administrativa y académica orientada al apoyo operativo y las decisiones.

El vocablo información tiene varias acepciones, pero existe un acuerdo generalizado que incluye no solamente datos estructurados sino también texto libre, gráficos, sonidos, fotografías, videos, films, etc. La información educativa es toda información que se relaciona con los hechos educativos y, por lo tanto, es de índole variada. Por ejemplo, comprende:

i. Datos demográficos e información sobre determinantes sociales, culturales, económicos y ambientales de la educación;

ii. Datos de alumnos atendidos, ingresantes, ingresantes efectivos, regulares, perfiles de ingreso y graduación, movilidad, retención, desgranamiento y similares;

iii. Resultados provenientes de evaluaciones y estadísticas de todo tipo,

iv. Datos del personal docente, de investigación, extensión y transferencia y datos del personal no docente en cantidad, calidad, dedicación, niveles de capacitación, edad, sexo, antigüedad, etc.;

v. Características de los planes y programas de estudio de pre grado, grado, postgrado y doctorados;

vi. Poblaciones atendidas y no atendidas;

vii. Presupuestos, costos, estructuras patrimoniales y proyecciones económicas y financieras;

viii. Edificios y recursos materiales de diverso tipo y, en su caso, con sus respectivos inventarios;

ix. Acciones complementarias a la función docencia 
x. Acciones de extensión, investigación, bienestar estudiantil, transferencia, etc.;

xi. Registros de asistencia, de progreso en los estudios y similares

xii. Legajos de docentes y alumnos;

xiii. Responsables estructurales, funcionales o no, por la información y los sistemas de información

xiv. Todo tipo de información cruzada y de relación inherente a la actividad educativa.

Como componentes esenciales de las organizaciones educativas, los sistemas de información están incluidos en todos los modelos de evaluación de la calidad y son tomados en cuenta como predictores para el alcance de los resultados; constituyéndose, como se ha dicho, en importante e imprescindible dimensión en los procesos de evaluación y acreditación de la educación universitaria.

Es interesante ver las falencias de los sistemas de información con referencia a los procesos de evaluación. La evaluación es un instrumento de gestión. Supone algún tipo de acción: ¿Por qué y para qué evaluamos?; ¿Podemos hacerlo sin información? El control, los diagnósticos, las reflexiones sobre los hechos educativos y la innovación requieren sistemas de información propios. Si bien no se conoce adecuadamente ni totalmente el objeto a evaluar (la institución educativa) por su complejidad; en la mayoría de los casos, los informes de evaluación son descriptivos, sin reflexión crítica sobre sí mismos y con datos sólo cuantitativos, con escasa información sobre las tensiones, las cuestiones y contradicciones que genera el tejido relacional propio de las organizaciones educativas. La evaluación, ¿ha reemplazado a la planificación sin recrear el conflicto?; ¿Qué se evalúa, quién y cómo?; ¿Cuál es el modelo subyacente?; Las evaluaciones, ¿Son trasvasadas por cuestiones políticas? En coincidencia con varios de los autores que luego se citarán en cada caso, estimo que todo esto dificulta los nudos a estudiar y modificar para innovar, cambiar, mejorar, etc.

Redefinir a las instituciones educativas como organizaciones que aprenden, en la línea de los trabajos de Senge, Argyris, Weick, Schón, Hargreaves; Bolívar, Gairín, etc., como estrategia de cambio en la postmodernidad y para institucionalizar procesos de renovación, torna necesario renovar el propio concepto de aprendizaje organizacional aplicado a las mismas, configurándose éstas como unidades de formación e innovación. Para ello, en su seno, el entorno, las relaciones de trabajo, la capacitación sistemática del personal y los sistemas de información deberán contribuir al "ideal de desarrollo y a la fijación de una trayectoria a seguir". La información y los sistemas de información educati- 
vos pueden ser factores que fomenten y potencien el proceso de aprendizaje organizacional en escuelas y universidades o lo inhiban, obstaculizando la reconstrucción educativa en que las comunidades están empeñadas.

Frases, como las siguientes, no son difíciles de encontrar en los documentos y textos de Administración de la Educación, así como en los informes elaborados por expertos:

Entre las principales falencias encontradas se verifica el hecho de que los registros y la información para las decisiones se encuentra atrasada, desordenada, repetida y no es confiable ni completa. Se recomienda perfeccionar los sistemas de información de modo que sirvan para las decisiones operativas de la institución y como apoyo al proyecto institucional".

"Entre las debilidades mas importantes aparecen los sistemas de información implementados en la universidad. Entre ellos, la información contable no es fácilmente comparable con el presupuesto. El control presupuestario es malo.

No existe plan de capacitación ni detección de necesidades en los procesos de trabajo y, en particular, con relación a los sistemas logísticos o de apoyo y de información.

La institución carece de indicadores y de sistemas de información adecuados para evaluar calidad y productividad de los procesos sustantivos. En algunas áreas, la información parece suficiente y se cuentan con sistemas de información bastante consolidados pero existen problemas para satisfacer nuevas necesidades de información, para planificar y evaluar a la institución como un conjunto.

Ausencia generalizada de un análisis sistemático de los procesos de gestión y servicios centrales y de sus resultados y escasa atención a las opiniones de los usuarios que requieren información para el trabajo cotidiano y para sus decisiones.

Escasa coordinación vertical y horizontal en los servicios y en los sistemas de información para la gestión y existencia de información fragmentada e incompleta.

(CONEAU, 1997/2006).

La comprensión de la calidad requiere información relevante y diversificada. Información que ilustre y eduque en primer lugar a los directamente implicados en los procesos educativos y, en segundo lugar, el resto de la sociedad. Una información, en fin, que debería estar al servicio de la educación y el conocimiento profundo y enriquecedor del sistema educativo. (FÉLIX ANGULO, J., 1996)

Se encuentran en proceso de implementación sistemas de información pero no se puede asegurar su utilidad institucional aún, dado que 
los usuarios han detectado inconvenientes para su uso y por el hecho de que fueron diseñados para otros tipo de entidades. (Adaptado de textos sobre la realidad de la gestión educativa)

Los sistemas de información en nuestra institución son, prácticamente, inexistentes e inútiles en su calidad decisional. Carecemos de información referida al déficit ya que se trabaja en el día a día y existen otras casos y situaciones con referencia a datos de cuestiones académicas y administrativas lamentables. (Parte de las declaraciones del rector de la Universidad de Buenos Aires, Dr. Rubén Hallú, transmitidas en emisiones televisivas del día 13 de febrero de 2007 y publicadas, previa adaptación, en los periódicos argentinos al día siguiente.

Deben desarrollarse nuevos e innovadores modelos de gestión educativa y escolar con sistemas de información adecuados tendientes al fortalecimiento de las escuelas y universidades y a la organización de procesos participativos de docentes, padres y comunidades locales [...]. Entre los desafíos para las universidades y sus áreas prioritarias, hay que mencionar nuevas modalidades de conducción y nuevos sistemas de información para la adopción de decisiones de modo que se pueda ayudar a la evaluación como proceso permanente y continuo y a los procesos de integración regional y de convergencia educativa. [...] La construcción de un espacio común latinoamericano de educación superior requiere, entre otras cuestiones, superar la fragmentación, nuevos modos de gestión, flexibilidad en los diseños, incrementar procedimientos de doble titulación y trabajar en común para la movilidad académica y profesional. Se trata de cuestiones y alianzas estratégicas, con estructura administrativas eficaces para ello." (Norberto Fernández Lamarra: Cuadros resúmenes. "Reflexiones sobre la educación y la escuela necesaria", Ciclo: De la escuela actual a la escuela necesaria, UNTREF, Buenos Aires, 2005, y conferencia "La construcción del espacio común latinoamericano de educación superior y su convergencia con el europeo. El rol de las universidades, Universidad Nacional de La Plata, junio de 2006).

La ineficacia e ineficiencia en los sistemas de información es uno de los problemas de la administración educativa en América Latina." (ARISMENDI POSADA, 1995). 
Durante los últimos años, se ha instalado la idea de la importancia de los sistemas de información en la estrategia organizacional y, en nuestro caso, para la calidad educativa como un factor básico en la obtención de nuevas oportunidades y en la resolución de desafíos crecientes en un mundo cambiante. El entorno donde se desarrollan sus actividades que se vuelve cada vez más complejo, la creciente globalización, el proceso de internacionalización, el incremento de la competencia en los mercados educativos y laborales, la rapidez en el desarrollo de las tecnologías de información, el aumento de la incertidumbre en el entorno y la reducción de los ciclos de vida de los productos o servicios y en el caso educativo, la masividad de la enseñanza, los cambios en el sistema, el nuevo rol de la escuela y de otras instituciones educativas y la implementación de procesos de evaluación, acreditación y convergencia originan que la información se convierta en un elemento clave para la gestión, así como para la supervivencia y crecimiento institucional. (Adaptado del material didáctico de la cátedra de Administración de la Educación y de las Instituciones Educativas, $\mathrm{FH}$ y $\mathrm{CE}$, UNLP)

En el trabajo de Roberto Martínez Nogueira, con la colaboración de Norberto Góngora, "Evaluación de la gestión universitaria", -Informe para la CONEAU, Argentina, año 2000-, se mencionan las particularidades de la dimensiones Gobierno y Gestión, entre otras, y el peso de variables tales como: a) La disponibilidad de la información para la adopción de decisiones; b) El grado de informatización de los sistemas administrativos; c) La existencia de información estadística y su actualización, adecuación, divulgación y uso; d) La calidad de la información presupuestaria; e) El grado de desarrollo de la unidad ó área de la estructura que administra los sistemas de información, etc. De este trabajo y otros similares mencionados aquí, se deduce que valorar la información y los sistemas de información relevantes y diversificados es imprescindible para la calidad educativa.

En el artículo de Alicia Vales, "La construcción de un sistema de información socio educativo", REPLAD-OREALC, que tiene como objetivo discutir sobre su utilidad para el proceso de gobierno de la educación en el Ministerio de Educación, se señala que,

en los sistemas de información, en sentido amplio, se reconocen tres dimensiones: a) Una temática, visualizada como un conjunto de datos organizados de acuerdo con un modelo analítico de los fenómenos sobre los cuales informa; b) Una técnica desde donde se da cuenta de las prácticas formales e informales de producción de información y la organización de los recursos aplicados a ella; y c) Una institu- 
cional, referida a la distribución formal e informal de competencias respecto a la producción de la información y a la configuración de los canales por los cuales circula. Este sistema está concebido como una intervención político-técnica, que muestra desconexiones entre las áreas pero que siempre alimenta los procesos organizacionales y administrativos en cada nivel de gestión.

La profesora Vales comenta algunas características, tales como el hecho de que las organizaciones educativas son productoras y usuarias de la información al mismo tiempo, la existencia de canales horizontales de circulación de la información, la incorporación de información del contexto, la consideración de la importancia de la información no formalizada en este tipo de instituciones y los modos de retroalimentación.

En el libro de Delia Azzerboni y Ruth Harf "Conduciendo la escuela - Manual de gestión directiva y evaluación institucional", Ediciones Novedades Educativas, Buenos Aires, 2003, y en el "Manual de organización de instituciones educativas” compilado por Domínguez Fernández y Mesanza López, Editorial Escuela Española, Madrid, 1996, se plantean la importancia de la información, los sistemas de información y del proceso de comunicaciones así como el papel y la responsabilidad de los diversos actores institucionales en la producción y distribución de la información. En el primero de los textos citados, las autoras dejan en claro que "nadie puede hacer más que aquello para lo cual posee información" y que los obstáculos existentes, tanto en las comunicaciones como en los sistemas de información, deben superarse en aras de la calidad. En el Manual aludido, se analizan los factores que intervienen en los procesos de comunicación y evaluación como base para la elaboración de estrategias de innovación y mejora de la calidad y se comentan los problemas de control, ambigüedad y sobrecarga de información así como el problema cultural y de las actitudes de los distintos actores asociados, tanto en lo formal como en lo informal, y que pueden impedir comunicaciones efectivas y sistemas de información eficaces para las instituciones educativas.

En la obra de M. Santos Guerra, "Entre Bastidores, el lado oculto de la organización escolar", Ediciones Aljibe, también se reflexiona sobre la importancia de los datos y la información para transformar los centros educativos españoles comprendidos en los niveles educativos previos al universitario. En el capítulo 18, el autor expresa:

El carácter disperso, fragmentario y, a veces, contradictorio de los datos exige la aplicación de procesos de contraste para analizar las 
discrepancias y las coincidencias de las explicaciones. No se trata de eliminar las discrepancias cuanto de comprenderlas y explicarlas. En un centro educativo, se dan múltiples visiones e interpretaciones de la realidad. La evaluación ha de integrarlas en una explicación coherente, no necesariamente uniforme. Los procesos de triangulación de datos procedentes de diversos métodos, de distintos informantes, de momentos distintos, de opiniones de agentes internos y externos, etc. facilitan el contraste y la depuración de tales datos y ayudan a obtener nuevos datos o mejores precisiones con el fin de obtener información más elaborada que favorezca la redacción de informes con valor para las decisiones.

En documentos referidos a la creación de un espacio común latinoamericano y europeo para la educación superior, así como en las reuniones internacionales de los docentes e investigadores que intervienen en proyectos tales como TUNING, 6X4 UREALC, etc., también entramos comentarios al respecto similares al ya citado del Prof. Fernández Lamarra. Sin agotar la nómina, se reproducen algunos, a continuación:

Carecemos de información confiable para comparar créditos académicos y para ayudar a la movilidad de docentes y alumnos. La construcción de los sistemas de créditos académicos y el complemento al título, la evaluación por competencias y las estrategias para la investigación e innovación dependen de sistemas de información compartidos y compatibles entre las universidades. (Adaptado del material entregado en el Tercer Seminario Internacional de Seguimiento del Proyecto $6 \times 4$ UEALC, Seis profesiones en cuatro ejes: Un diálogo universitario, Mendoza, Argentina, 26 y 27 de oct. 2006)

Los resultados presentados muestran una fotografía de la importancia y viabilidad de los nuevos desarrollos en los sistemas de educación superior en América Latina que se encuentran en una primera etapa de planificación e implementación [...]. También muestran un amplio apoyo a una mayor colaboración en la región latinoamericana y con Europa mediante el desarrollo de una comunidad de educación superior y el establecimiento de unos sistemas (v.g.: referido a la información educativa) y políticas regionales en la materia. Existe apoyo para ampliar la cooperación institucional [...]. Se requieren nuevas políticas, programas e instrumentos a nivel regional, nacional e internacional para fomentar la movilidad social, reconocer grados y certificaciones, usar competencias, reconocer sistemas de acreditación y desarrollar sistemas de créditos académicos. Es importante construir sobre las experiencias existentes y las buenas prácticas de las agencias gubernamentales y de las instituciones de educación 
superior en muchas de estas tendencias. Es igualmente importante tomar ventaja de nuevas herramientas, modelos, marcos, redes de comunicación e información que se van desarrollando mediante proyectos e iniciativas innovadoras conjuntamente en Europa y América Latina. (JANE KNIGHT, 2006)

Aunque las relaciones y los intercambios entre universidades, profesores y científicos europeos, tanto dentro de Europa como con el resto del mundo, son hoy muy importantes, las universidades europeas siguen manteniendo estructuras organizativas y modelos educativos muy diferentes, en poca sintonía con los procesos de integración europeos y con las demandas de un mundo globalizado. La diversidad de los sistemas de Educación superior ha sido considerado como un bien muy valioso que no debía ser perturbado, El valor de la diversidad está consagrado por los tratados constitutivos de la Unión Europea que expresamente señalan que la educación es una prerrogativa de los estados miembros, Sin embargo, aunque es cierto que la diversidad de la educación superior es un valor importante que conviene mantener, parece razonable que esta diversidad sea compatible con ciertos niveles de comparación entre los sistemas de educación superior (incluyendo la información) que faciliten la convergencia que estamos viviendo en casi todos los otros aspectos de nuestros sistemas sociales y económicos. Por otro lado, los sistemas europeos de educación superior se han caracterizado por su opacidad. Su escasa transparencia, en general, es consecuencia del tradicional carácter burocrático y funcional de estos sistemas. En efecto, de una y otra forma, los sistemas europeos son dominantemente públicos, sometidos a una detallada regulación estatal (cuando no son parte de la propia administración del Estado, como en el caso de la universidad napoleónica tradicional), con profesorado funcionario público y, en muchos países confiriendo títulos de carácter nacional con títulos que además tienen validez profesional. Estos mecanismos reguladores han hecho que los sistemas de educación superior europeos sean bastante homogéneos dentro de cada país, sin grandes diferencias aparentes de calidad, lo que ha impedido, o al menos dificultado, la aparición de universidades de calidad muy pobre. Ciertamente este es el resultado positivo de un sistema burocratizado pero el lado negativo es que las universidades europeas, en general, tienen poco desarrollados los mecanismos de rendición de cuentas, los sistemas de información internos y para los ciudadanos o los mecanismos para atraer "clientes" que son tan típicos en otros sistemas de educación superior $[\ldots]$.

Entre los aspectos de que deben acompañar un plan de calidad en las universidades se señala el establecimiento de un sistema de información pública sobre las titulaciones mediante un catálogo de 
más de cincuenta indicadores para informar a usuarios internos y externos $[\ldots]$.

[...] Es necesario facilitar información pertinente y fiable sobre la calidad de las instituciones, sus programas, servicios y niveles científicos $[\ldots]$.

[...] Uno de los principales problemas con que se encontraron las unidades evaluadas fue la falta de información y la falta de fiabilidad de los datos precisados para la evaluación. A través del Plan Nacional de Evaluación de la Calidad Universitaria, en España, ha habido mejoras generales en este tipo de información y se ha incrementado su uso en la administración interna de las instituciones. Sin embargo, es necesario trabajar más en estos temas y se necesita llegar a acuerdos con todos los departamentos administrativos para poder mejorar el flujo de información necesitada (tanto en las instituciones como en las áreas de administración pública) para la toma interna de decisiones y, sobre todo, para facilitar una información cada vez mas importante para el público en general [...]. (GINÉS MORA; FERNÁNDEZ LAMARRA, (Coords.), 2005).

Para su transformación, la universidad debe atender demandas globales, aumentar el número de plazas, mejorar calidad, incentivar investigación, optimizar extensión, promover liderazgos, brindar servicios educativos para toda la vida, centrarse en el aprendizaje y en la formación de competencias, redefinir su misión y sobre todo, por la dinámica de las relaciones y la velocidad de la información, debe contar con estructuras de gestión y sistemas de información para decisiones transparentes, ágiles y efectivas y para un proceso continuo y atento de evaluación capaz de medir los grandes objetivos que se alcancen. ( PANIZZI, 2006).

En el Capítulo V,"Enfoques Metodológicos", del libro de Norberto Fernández Lamarra, "Educación superior y Calidad en América Latina y Argentina", IESALC/UNTREF, Bs. As., 2007, se desarrollan todas las Dimensiones comunes que se utilizan en los procesos de evaluación y acreditación que surgen de los informes nacionales analizados de varios países latinoamericanos. Ellas son: 1) Filosofía, misión y visión institucional; 2) Plan de desarrollo institucional; 3) Normas internas y reglamentos; 4) Carrera y programas académicos de grado y/o postgrado; 5) Estructuras de gobierno; 6) Actividades de investigación; 8) Actividades de extensión e interacción social; 8) Personal académico; 9) Recursos humanos administrativos y servicios técnicos de apoyo; 10) Servicios de atención estudiantil; 11) Recursos físicos; 12) Recursos financieros; 13) Capacidad institucional de autorregulación; 14) Comunicación y transparencia; 
15) Cantidad de alumnos de grado y/o postgrado; 16) Convenios de cooperación y 17) Capacidad de innovación e incorporación de nuevas tecnologías. Asimismo, se analizan los Sistemas Informáticos de Gestión Universitaria de IESALC/UNESCO (Software) que se encuentran a disposición de instituciones, funcionarios y especialistas. Aquí, el autor incluye comentarios sobre los siguientes: a) Sistemas de acreditación de programas académicos, realizados por los Profesores Orozco Silva y Cardoso Rodríguez de la Universidad colombiana de Los Andes; b) Diagnóstico de universidades e instituciones de educación superior (Matriz FODA); c) Software de gestión universitaria, desarrollado por la Universidad Tecnológica de Panamá; d) Software para la evaluación del currículo, basado en el "Manual de procedimientos para pares evaluadores" aprobado en el Mercosur y desarrollado por la Universidad Autónoma de Asunción del Paraguay; e) Software para autoevaluación de estudiantes, realizado en colaboración con la Asamblea Nacional de Rectores y el Ministerio de Educación del Perú; f) Sistema de autoevaluación de instituciones universitarias latinoamericanas y del Caribe (SAIULCA) diseñada por la Ing. Trinidad Urban, a partir de una investigación realizada por la Asociación Dominicana para el Autoestudio y la Acreditación.

En el trabajo coordinado por José-Ginés Mora y Norberto Fernández Lamarra, citado anteriormente, y donde se incluyen documentos de expertos en evaluación y acreditación de España, Italia, Países Bajos, Portugal, Argentina, Brasil, Uruguay, etc., se señalan en otros párrafos los problemas y las dificultades existentes para

- Establecer criterios comunes en cuanto al valor de los créditos (unidades de estudio de los alumnos)

- Homologar títulos

- Incrementar la movilidad al final de las carreras y más aún, la movilidad estudiantil durante el ciclo educativo

- Lograr competencias profesionales mas o menos aceptables y compatibles entre los distintos países

- Reconocer estudios que conducen a la formación que tiene como resultado las competencias profesionales aludidas

- Realizar las comparaciones y compatibilidades que, en el campo educativo, exige la globalización

- Establecer sistemas de evaluación y acreditación conjuntos o mas o menos comunes que se constituyan en una herramienta eficaz para la integración real

- Realizar auditorias institucionales de calidad 
En el artículo de Norberto Fernández Lamarra y Mariana Alonso Bra "La gestión universitaria en la Argentina: Una aproximación a partir de la evaluación institucional externa", publicado en Collossi, Nelson y Días de Souza Pinto, Marli (organizadores): "Estudos e Perspectivas em Gestäo Universitaria” INPEAU-UPSC, Nova Letra, Blumenau-SC, 2004, los autores explican que

En los informes, la gestión administrativa de las universidades se pretenda con problemas que podrían resumirse como la falta de desarrollo técnico y racional. Lo que, antes que una limitación simplemente operativa debe ser interpretado a partir del diagnóstico de los restantes planos de la gestión. Es decir, creemos que las dificultades para definir, en el consenso, un proyecto institucional compartido y la falta de integración institucional (interna y externa) desproveen de un marco institucional preciso o consolidado a la gestión administrativa, indispensable para que ésta gane en coherencia y se fortalezca. Por ello, muchas de las dificultades que las universidades afrontan en lo administrativo se explican mas desde lo político, el gobierno y lo institucional que desde la propia gestión administrativa. Frente a las debilidades en lo político y en lo institucional, lo administrativo se caracteriza por su falta de consolidación, por su desarrollo azaroso -con criterios y orientaciones yuxtapuestos o contradictorios- y por sus inercias, desequilibrios y desconexiones.

Mas adelante, los autores clasifican las observaciones de los informes de evaluación externa en: a) Cuestiones vinculadas al fortalecimiento cuantitativo y cualitativo de lo administrativo; b) Cuestiones vinculadas puntualmente a la administración de recursos materiales y c) Cuestiones respecto del desarrollo de insumos directamente involucrados en el quehacer académico. En un Anexo del mismo trabajo, se incluye un listado de las dificultades mencionadas en los informes referidas al tema que nos ocupa. Entre ellas, encontramos:

- Insuficiente o inadecuada producción y circulación de información en el conjunto de la comunidad universitaria y como herramienta para las decisiones académicas y para la participación colectiva en la gestión.

- Insuficiente desarrollo informático y desequilibrios en la distribución de los recursos informáticos sin estimaciones de costos que permitan optimizar

- Insuficiente apropiación de la capacidad instalada y resistencia para extender las herramientas informáticas a los ámbitos administrativos.

- Falta de criterios y políticas comunes para la gestión de los sistemas de información $[\ldots] "$ 
Estos y otros problemas parecen ocasionados por sistemas de gestión poco eficaces y sistemas de información incompletos, incompatibles para el procesamiento de datos que provengan de distintas fuentes y poco confiables. Existen sistemas de educación superior faltos de elementos imprescindibles, como los sistemas de información, para satisfacer necesidades de las sociedades actuales en un nuevo contexto donde las universidades sean referentes atractivos para docentes, estudiantes y graduados de distintos países y regiones y donde, como dadoras y demandantes de información, tomen conciencia de esta cuestión vital para su futuro. Estimo que se ha demostrado que son notables las coincidencias, sobre el tema que nos ocupa, que es posible encontrar en artículos y textos escritos por expertos que trabajan e investigan en contextos distintos y en distintos niveles de sus respectivos sistemas educativos y que tienen objetivos pedagógicos también distintos.

\section{Repasemos algunas cuestiones}

I) Comunicación e información son términos de una misma familia. Mientras el primero constituye un proceso, la información es la sustancia del mismo. La información es aquello que es comunicado siempre que Incremente el conocimiento del receptor; es decir, quite o reduzca la incertidumbre, sea desconocida y comprendida por quien la recibe y tenga valor de uso (relevancia) para el receptor. La información es el conocimiento, unido a la inteligencia, que se requiere y utiliza para intentar lograr metas y objetivos. Se constituye no por hechos o eventos aislados sino por la relación estructurada de eventos. En sus diferentes manifestaciones, debe proporcionar y constituirse en un ingrediente básico para la adopción de decisiones. El manejo de la información debe implicar alguna clase de procesamiento, adaptación e intercambio; es decir, se necesita de un sistema de información. En las organizaciones educativas de la educación superior, la preocupación permanente por la mejora de la gestión condujo a la de sistemas automáticos, con su consecuente información, capaces de facilitar tareas mecánicas y rutinarias, evitar errores y mejorar controles; con el incremento consiguiente de la calidad, pero parece no ser suficiente en las actuales circunstancias. Una de las causas puede ser que ser el hecho de que se gestionan por separado el o los procesos de comunicación institucional, los sistemas de información educativos que se implementen y el procesamiento distribuido de los datos. La calidad técnica de los dos últimos se puede invali- 
dar por los problemas semánticos, psicológicos, sociológicos y técnicos de los procesos aludidos. Por otra parte, existen problemas de atraso tecnológico, de diseño, de participación adecuada de los usuarios y de capacitación de todos los involucrados.

II) El problema que enfrentan muchos directivos educativos es el de sufrir escasez de información, a pesar de que seguramente cuentan con una verdadera sobreabundancia de datos; éstos, por sí mismos, no reducen la dosis de ignorancia o el grado de incertidumbre de quien tiene que adoptar una decisión. Un dato aislado o un conjunto de datos se transforma en información cuando una persona o grupo le asigna significado; por ello, se ha popularizado la idea de que Información es el significado que una persona asigna a un dato; luego, la información es un dato o un conjunto de datos evaluados por un individuo concreto que trabaja, en un momento dado, sobre un problema específico, para alcanzar un objetivo determinado. En consecuencia, lo que constituye información para un individuo en un caso específico puede no representarlo para otro o incluso para el mismo individuo en un momento distinto o frente a un problema diferente. Este tema es clave, ¿Cuántos son los administradores, directivos o gestores educativos que tienen en claro que información necesitan, la saben pedir adecuadamente y establecen un diálogo fructífero y enriquecedor con analistas, programadores y expertos en informática?

III) A su vez, la información es un recurso y se la debe tratar como tal: un recurso con costos y beneficios conexos. Por lo tanto, se deben tratar las decisiones relativas a la adquisición de información adicional en la misma forma en que se trata a la decisión de comprar una máquina cualquiera; es decir, se debe establecer una comparación entre los beneficios a lograr de la información adicional y los costos de la compra. Eso sin olvidar que el procesamiento de la información (que puede incluir la adquisición, el almacenamiento, la transmisión y la entrega al decididor), requiere inversiones de tiempo, recursos e instalaciones. Pero a pesar de considerarse un recurso, es un bien que difiere de un bien económico al no acabarse o depreciarse al ser consumido. La información no se extingue al ser compartida, por el contrario, esto la hace crecer. Aquí estamos ante un punto crucial. La universidad es creadora y transmisora de información pero ¿Cuántos son los que en realidad la comparten con verdadero espíritu universitario y cuántos son los directivos educativos que la distorsionan para justificar sus acciones por temor a las evaluaciones externas? 
IV) Como se ha indicado, el concepto de información subraya la idea de que se comunica algo valioso (conocimiento, inteligencia, etc.) a algún individuo, grupo u organización. Es necesario, pues, habilitar los medios para convertir los datos en información. Éste es, precisamente, el papel del sistema de información. Y, aquí también otros interrogantes, a modo de ejemplo: ¿Qué decisiones y previsiones presupuestarias se ha realizado en los últimos años que realmente tiendan a comunicar valor tanto en la universidad para su consumo interno como para la interrelación de la misma con la comunidad y los otros niveles del sistema educativo? ¿Qué valor realimentador han tenido para el nivel medio, secundario o polimodal los resultados de las evaluaciones a los alumnos ingresantes a la universidad y cuántos han sido los programas de articulación implementados a partir de ello?

V) Un sistema de información es un subsistema de la organización definido y caracterizado por poseer:

1 Un objetivo general, el de constituir junto con los subsistemas de decisión un sistema de control aplicado a un sistema de referencia. Por ejemplo, un sistema de información que de cuenta de las escuelas de nivel medio donde provienen los alumnos universitarios posee como referencia al sistema de ingreso.

2 Un objetivo operativo, el de producir informes para la decisión de los distintos niveles que conforman la estructura organizacional de la institución educativa.

3 Varios elementos: A los conocidos de cualquier sistema organizacional (recursos humanos, financieros, tecnológicos, materiales, mecánicos, etc.) se le adicionan: Datos, Soportes de datos o archivos, Medios de procesamiento e Información resultante.

4 Entradas constituidas por los datos originales o el resultado de otros procesamientos vinculados con los objetivos operativos aludidos.

5 Salidas: Informes

6 Estructura: Registro de datos, archivos, redes, etc.

7 Plan de acción: Programas, procedimientos, interfases, etc.

VI) Un sistema de información está formado por componentes que llevan a cabo funciones tales como las de captación, recolección o recogida de datos, clasificación, compresión, almacenaje o archivo, administración, procesamiento o transformación, transmisión y recuperación, exposición o presentación de los datos o la información. Como se ha indicado varias veces, su finalidad es proporcionar información a fin de adoptar decisiones y para facilitar la coordi- 
nación entre las diversas actividades. Los sistemas de información, en sentido restringido, incluyen todo procesamiento programado de información pero en sentido amplio incluye a todos los componentes humanos y mecánicos involucrados en la coordinación y adopción de decisiones. Para que la información resulte eficiente, debe reunir una serie de requisitos de modo tal que la utilidad que proporcione justifique el empleo de los recursos que se hubieran aplicado para producirla.

Los requisitos que presentamos a continuación son, al mismo tiempo, una lista de criterios generales para guiar el diseño de sistemas de información y para evaluar el funcionamiento de los mismos.

Economía o Costo: se mide desde el punto de vista de la utilidad que la información tiene para la organización. El costo de producir una información no debe ser superior al beneficio esperable de su utilización.

Utilidad: Toda salida de un sistema de información debe satisfacer una necesidad y debe ser considerada innecesaria mientras no se compruebe su utilidad. Esto significa que todo directivo, docente, investigador o analista habrá de mantener una permanente actitud adversa a la creación de nuevas salidas computarizadas (como listados o pantallas), o de nuevos formularios para integración y procesamiento manual que no se justifiquen.

Oportunidad: Está referido al momento en que la información se halla disponible. La información es necesaria, tiene valor, en un momento determinado. La información debe estar disponible en el momento en que se la requiera. Este requisito hace referencia al momento y a la frecuencia con que la información debe ser suministrada porque cada decisión tiene su tiempo de respuesta admisible. El valor de la información se torna nulo si no se usa en el lapso adecuado.

Corrección: Es la adecuación de la información con la decisión que se ha de adoptar. Es la precisión necesaria para mantener el valor de la decisión basada en la información suministrada. Algunas veces corrección se asemeja a exactitud; otras, no. La información correcta es la mejor prueba de la mejor decisión.

Relevancia: Relevante proviene de "relevare" se significa levantar, alzar, destacar, otorgar excelencia o sobresalir. La relevancia destaca la significación relativa que una información debe tener para la decisión. Una información con datos no significativos no sirve para actuar, se requieren datos relevantes. Un directivo puede disponer de mucha información pero sólo usará la importante o relevante, la que tenga valor de uso, la que represente un foco de atención 
para él, la que le permita actuar en un sentido dado y conforme el problema que enfrente. La información que se procesa debe siempre ordenarse por importancia y no presentar "hojarasca". La relevancia no sólo debe ser un atributo propio del dato (o de la información) sino que debe ser reconocido y conferido por el sistema de información.

Excepción: Lo excepcional es aquello que se separa de la norma o de la condición general de su especie. La información que debe llegar a los niveles de decisión es la excepcional pues, de otra manera, su volumen torna imposible su lectura y análisis. La característica de excepcional, que debe ser fijada para cada tipo de información y para cada momento o problema particular, posibilita la presentación de resúmenes para que la información de salida sea legible y fácil de manejar. Informar por excepción es informar para actuar. Significa trabajar sobre las distorsiones para corregir y orientar en otro sentido al que la realidad manifiesta. Lo que difiere de lo normal requiere análisis y una acción determinada. El problema es elegir y comprender el parámetro que representa lo "normal" para definirlo y calibrarlo adecuadamente y tener perfectamente, determinados los desvíos aceptables.

Comparatividad o comparabilidad: El valor de la información, respecto de la decisión, se incrementa notablemente mediante la referencia de la misma con los objetivos que hacen a la decisión. Es mucho mejor brindar siempre información en términos relativos. Por ejemplo, cuando suministramos información sobre costo por alumno, etc. se mejora su valor si la comparamos con los objetivos perseguidos y con lo ocurrido en otros períodos similares y si señalamos la tendencia que siga el resultado en el transcurso del tiempo. Las cifras aisladas o absolutas no siempre dan la idea correcta de hasta donde resulta satisfactorio el rendimiento alcanzado. La información debe ser comparable en el espacio, en el tiempo y en el alcance. En el espacio implica, por ejemplo, que la información de una cátedra debe ser comparable con la de otra; no habría comparabilidad, por caso, si los resultados del aprendizaje se expresaran en unidades distintas; deben compararse entidades semejantes (Uniformidad). La comparabilidad en el tiempo significa que la información de un período debe ser comparable con la de otro (Periodicidad). Cuando los administradores deciden eligen entre varias alternativas de acción como consecuencia de la comparación, análisis relativo o relatividad de la alternativa elegida con las restantes, con resultados definidos como mejores para la seleccionada. La relación, correlación o referencia a otros datos del mismo tipo, sean históricos o proyectados, o afines al dato suministrado permite ponderar su valor relativamente a un contexto dado. 
La comparatividad, entonces, busca proveer a la información de un cierto dinamismo que pueda no surgir del dato aislado, el que, en su soledad, no alcanza a proporcionar el panorama que surge de la comparación.

Flexibilidad: Todo sistema de información debe ser adaptable a los cambios del sistema-objeto o de referencia. Este requisito está indisolublemente vinculado con la satisfacción de las cambiantes necesidades de información de los administradores y de la organización toda. El alcance y la conservación de un apropiado grado de flexibilidad del sistema de información tienen notables influencias en (y dependen en alto grado de) la metodología y las herramientas que se habrán de emplear para su diseño y mantenimiento.

Comprensibilidad y claridad: La información debe ser comprensible y clara. Se deben evitar problemas de sofisticación en exceso; muchas veces demostrable. No se debe olvidar que el destinatario de la información debe encontrarse siempre en condiciones de comprenderla y, así, poderla utilizar con todas sus virtudes. La información debe atender al nivel intelectual y técnico del destinatario. El postulado precedente podría completarse diciendo que también deben tenerse en cuenta el lenguaje y las preferencias del destinatario. Muchos informes están plagados de palabras que pertenecen a la jerga profesional de quien los elabora, y no a la de quien deberá comprenderlos y utilizarlos. La sofisticación y el tecnicismo son problemas de las comunicaciones muy importantes que deben ser resueltos adecuadamente por los que administran. Claridad y simplicidad ayudan a comprender y al aprendizaje, empleo y operación por parte de todos los empleados y usuarios de los sistemas. Es casi un axioma que la información que no se comprende es desechada o rechazada y un sistema de información que no es comprendido o no responde a las necesidades planteadas por los usuarios, hará que éstos lo dejen de usar o lo "saboteen", dedicándose, además, a difundir sus fallas o limitaciones.

Confiabilidad: La información debe ser lo suficientemente confiable como para adoptar decisiones basadas en ella. A este fin, deben empezar por ser confiables los datos primarios y sus sucesivas transformaciones, lo que significa que no deben contener o introducir errores derivados de factores conocidos. La calidad de un sistema de información está determinada, en buena parte, por la calidad de sus datos primarios. La confiabilidad implica que, para la adopción de decisiones, la información debe ser correcta, pero no necesariamente exacta (como se ha visto), lo que es más cierto cuanto más se asciende en la pirámide organizacional. A este respecto, debe tenerse en cuenta que, mientras 
la información tiende hacia la exactitud en progresión aritmética, el costo de lograr esa exactitud tiende a ascender en progresión geométrica.

Disponibilidad: exige la posibilidad de acceso a la información siempre que sea necesario. Esta posibilidad debe ser considerada cuando se realizan cambios de versiones o actualizaciones por las cuales se pierde información implicando graves pérdidas económicas.

Seguridad: llegando a establecer niveles de acceso a los sistemas en función del puesto del usuario en la estructura de la organización. Debe considerarse siempre la seguridad física de la información, (pérdida por desastres naturales, sabotajes, etc.), el uso fraudulento de la misma y la confidencialidad y protección de la intimidad de clientes, ciudadanos y empleados.

Rara vez los datos educativos se convierten en información educativa. Se registran, producen, mantienen y actualizan cantidades masivas de datos pero no siempre se utiliza plenamente la información potencialmente útil debido a que no existen mecanismos ni sistemas que la ponen a disposición de las personas adecuadas en el momento de decisión adecuado y en formatos fáciles de comprender y asignar valor. En el funcionamiento de los sistemas de información, los problemas mas graves tienen que ver con la captación, exactitud, corrección, clasificación, archivo, procesamiento y transmisión de los datos. Muchas veces los que operan se enfrentan a obstáculos referidos a la calidad de la fuente, validez, confiabilidad y consistencia de los datos, como sucede -por ejemplo- en el nivel universitario.

Un sistema de información, por definición, no necesita ser computarizado; sin embargo, la mayor parte de los sistemas de información más complejos, en la actualidad y prácticamente, no puede implementarse sin alguna forma de apoyo computacional y de telecomunicaciones. El alcance del despliegue de sistemas de información en el sector educativo no es bueno ni se adapta a las necesidades de las organizaciones educativas. (A modo de ejemplo, basta, simplemente, observar el problema que se ha generado en las Universidades que han comenzado procesos de autoevaluación o realizado evaluaciones externas). Los datos en exceso, rudimentarios o de baja calidad sobre todo si se los compara con otras áreas son fácilmente comprobables.

Las organizaciones educativas, como todas las restantes, utilizan distintos tipos de información. Una clasificación interesante se presenta en el libro "LA DIRECCION POR SISTEMAS", de M. Del Pozo Navarro. Editorial Limusa Wiley - Madrid - México. Es la siguiente: 


\begin{tabular}{|c|c|c|}
\hline TIPO/COMPONENTES & CONTENIDO & INTERROGANTES \\
\hline $\begin{array}{l}\text { Información } \\
\text { Normativa }\end{array}$ & $\begin{array}{l}\text { Normas técnicas, de conducta, actuación } \\
\text { administrativa, tratamiento, control, seguri- } \\
\text { dad, difusión, distribución, etc. Pueden ser } \\
\text { permanentes o transitorias. Comprende } \\
\text { también la estructura orgánica, los proce- } \\
\text { dimientos y las reglas de comportamiento } \\
\text { dinámico para la misma. }\end{array}$ & $\begin{array}{l}\text { ¿QUÉ debe realizarse? } \\
\text { ¿QUIEN? } \\
\text { ¿CÓMO? } \\
\text { ¿DONDE? }\end{array}$ \\
\hline $\begin{array}{l}\text { Información de } \\
\text { Planificación }\end{array}$ & $\begin{array}{l}\text { Objetivos y medios a los que han de aco- } \\
\text { modarse las actividades futuras, en orden } \\
\text { a conseguir fines. }\end{array}$ & $\begin{array}{l}\text { ¿CUÁNDO? } \\
\text { ¿CON QUE? }\end{array}$ \\
\hline $\begin{array}{l}\text { Información de } \\
\text { Relación }\end{array}$ & $\begin{array}{l}\text { Conocimiento de la acción de los factores } \\
\text { endógenos y exógenos. Contacto entre los } \\
\text { miembros de la organización. }\end{array}$ & ¿QUÉ PASA? \\
\hline $\begin{array}{l}\text { Información } \\
\text { Operacional }\end{array}$ & Resultados de la actividad. & $\begin{array}{l}\text { ¿QUÉ HA } \\
\text { OCURRIDO? }\end{array}$ \\
\hline $\begin{array}{l}\text { Información de Control } \\
\text { y Gestión }\end{array}$ & $\begin{array}{l}\text { Comparación entre información operacio- } \\
\text { nal o de actividades con la normativa y la } \\
\text { de planificación. }\end{array}$ & $\begin{array}{l}\text { ¿EN QUE GRADO } \\
\text { SE CUMPLE? }\end{array}$ \\
\hline Información Integrada & $\begin{array}{l}\text { Síntesis de información para uso formal } \\
\text { y periódico del que administra y dirige en } \\
\text { todos los niveles }\end{array}$ & $\begin{array}{l}\text { SINTESIS DE LO } \\
\text { ANTERIOR }\end{array}$ \\
\hline $\begin{array}{l}\text { Información de } \\
\text { Investigación }\end{array}$ & $\begin{array}{l}\text { Empleo de los medios y técnicas modernas } \\
\text { para ayudar a la adopción de decisiones } \\
\text { y a la planificación que realizan los di- } \\
\text { rectivos. }\end{array}$ & $\begin{array}{l}\text { ¿QUÉ PUEDE } \\
\text { OCURRIR? }\end{array}$ \\
\hline
\end{tabular}

\section{En resumen,}

a) Los sistemas de información deben brindar información económica, oportuna, correcta, relevante, excepcional, comprensible, uniforme, periódica, completa, confiable, simple, comparativa, etc. pero siempre adecuada al tipo de decisión a la que debe servir.

b) Debemos aprender a trabajar con telecomunicaciones interactivas y a compartir responsablemente entre educadores, especialistas y administradores educativos. Compartir y comunicar es una tarea fundamental. El trabajo en equipo responsable y el intercambio de datos e información requiere que todos los involucrados acuerden en cuanto canales de comunicación con un protocolo de intercambio y un lenguaje común, incluyendo alfabeto, palabras, frases y símbolos que expresen y asignen significados que todos entiendan. 
Creo que el contenido de lo expuesto en este "Apartado de Repaso" debe constituirse en un punto central a dominar por cualquier miembro de la comunidad universitaria que pretenda formar parte de equipos directivos o de administración o gestión.

\section{III}

La educación superior se encuentra en proceso de cambio para mejorar la calidad educativa y los servicios y para adaptarse a los procesos de evaluación, acreditación y convergencia. La tecnología informática, que ha registrado avances extraordinarios en los últimos tiempos, debe incorporarse a la Universidad de un modo ordenado y responsable considerando su doble carácter de consumidora y de productora de información. La universidad transmite saberes, desarrolla competencias y modifica conductas en todos sus miembros (alumnos, docentes, no docentes) y también en la comunidad porque a través de la investigación y extensión contribuye al desarrollo social.

Los sistemas de información educativos y los tipos de información aludidos deben mejorar la calidad de la información disponible e incluir:

- las aspiraciones de los individuos que componen la organización educativa o una parte de su estructura

- las aspiraciones de los grupos de interés que interactúan con la organización educativa

- una adecuada articulación ciencia y tecnología aplicada en éste área

- el poder producir planes, controlar los procesos educativos y

- la capacidad de transferir y procesar esa información.

Se podría decir entonces que el camino más natural para analizar cualquier sistema es comenzar por especificar su función principal, esto es, qué propiedades deberían ser observadas desde el punto de vista del usuario y qué actividades se necesitan dentro de organización educativa para facilitar esas propiedades externas o funciones.

El sistema universitario se encuentra modernizando sus sistemas de información (bibliotecas, conexiones en red, internet, intranet, etc.) aunque aún no han abarcado todos los servicios en áreas como Direcciones de Enseñanza, Oficinas de alumnos, Departamentos docentes, Administración del personal, etc., menos aún si queremos comparar créditos académicos, planes de estudios, etc., con 
otras instituciones. Se necesita no solo inversión en equipamiento, software, etc., sino también en capacitación del personal y diseños e implementaciones adecuadas. Su incorporación y el desarrollo consecuente, adecuadamente planificado, es una prioridad. Algunos sistemas implementados, en Argentina, son el SIU GUARANI, Sistema de Gestión de Alumnos y el SIU COMENCHINGONES, Sistema de Gestión Económico-Financiera. El sistema de gestión de alumnos "SIU GUARANI" ha sido seleccionado entre los cinco finalistas en la categoría Participación Ciudadana para los premios "Excelencia en Gobierno Electrónico EXCELGOB", según se informó a todas las Universidades en el mes de mayo de 2007.

Se ha podido constatar en los últimos años el ascenso en las estructuras formales de los responsables de los sistemas de información en ministerios y demás organismos públicos educativos, siguiendo una tendencia observable en las empresas privadas. Sin embargo, en las universidades debe mejorarse el clima, las relaciones y los procedimientos para la instalación y potenciación de los sistemas que nos ocupan. Así, cada vez más, se considera al responsable del área de Organización y Sistemas o de los Centros de Cómputos como un gestor y cada vez menos un técnico. Se desmitifica su función y se asume que el éxito de su trabajo depende de su capacidad de integrar, de manera coherente, las decisiones y planes sobre sistemas de información en la estrategia y en los proyectos institucionales educativos, con el apoyo y bajo el liderazgo de las autoridades superiores universitarias. Como se ha expresado, en este ámbito, todo administrador o gestor educacional y todo docente, investigador o extensionista es, al mismo tiempo, productor y consumidor de información, responsabilidad que también alcanza al personal no docente en las tareas de apoyo esenciales a la labor educativa. También los alumnos y graduados consumen información y sus respectivos centros cumplen un rol trascendente como productores y consumidores. En este punto, cabe destacar que existe un debate pendiente en el seno de las universidades que es al vez político, administrativo y tecnológico. Ese debate tiene que ver con decidir sobre la conveniencia de tener enormes centros de cómputos que concentren y procesen información de todas las facultades y restante estructura o si debe comenzar a implementarse sistemas de apoyo a las decisiones descentralizados, aunque integrados en su lógica de acción y en la cantidad y calidad de la información producida.

Para la gestión universitaria, no sólo es relevante el conocimiento de teorías, modelos, resultados de investigaciones y sus influencias sino que debe analizarse, discutirse y sistematizar la referida a rubros tales como: ¿Cuáles soluciones de software existentes son las mas convenientes para la gestión?; 
¿Cómo debemos organizar las redes y las telecomunicaciones al interior de la Universidad y entre universidades?; ¿Qué datos e información intermedia y final es posible compartir con otras unidades educativas?; ¿Quién y cómo se deben administrar las bases de datos compartidas?, etc. además de las cuestiones asociadas al servicio técnico, a la capacitación del personal, a las auditorias informáticas, etc. y, no menos importante: ¿quién decide acerca de la estructuración, el acceso y la seguridad?

Con referencia a la función docente, el diario Clarín publicó una nota el 25 de febrero de 2007 donde se alude a una investigación, patrocinada por Telefónica de Argentina donde participaron entre otros los Dres. Susana Finquelevich y Alejandro Prince, que revela que el uso extensivo de las TICs en las universidades privadas y públicas argentinas recién empieza. Aseguran que su ausencia se debe más a un cierto desinterés de autoridades y profesores que a la falta de presupuesto. Esta cuestión es conexa a la que nos ocupa y merece su propio análisis.

\section{IV}

Los objetivos de los sistemas de información educativos son:

- apoyar los objetivos y estrategias de la organización o institución, suministrando toda la información necesaria para su correcto funcionamiento. La información manejada abarcará desde la actividad rutinaria hasta aquella necesaria para el proceso de planificación a largo plazo y para implementar procesos de auto evaluación, evaluación externa, acreditación y convergencia.

- proporcionar información para el control de la totalidad de actividades, pudiendo comprobar el cumplimiento de las metas establecidas abarcando a todas las áreas y a la gestión global y sectorial de la entidad.

- facilitar, simplificar o realizar automáticamente procesos que tradicionalmente se realizaban de forma manual. Por ejemplo: Procesos de control presupuestario, registro de avance del aprendizaje, cómputo de recursos auxiliares para la docencia, comparación de créditos académicos, otorgamiento de equivalencias y reválidas, etc.

- adaptar las necesidades de información a la evolución de la organización; como por ejemplo, frente a una reforma de planes de estudio.

Para alcanzar sus objetivos, el sistema de información debe ser capaz de: 
$\checkmark \quad$ Recibir datos provenientes del interior de la universidad, del contexto y de otras universidades, con el menor costo posible y correctos, libres de error o defecto.

$\checkmark$ Evaluar la calidad e importancia relativa de los datos de entrada con filtros adecuados y jerarquías que posibiliten la racionalización de los recursos y el consiguiente beneficio operativo e institucional.

$\checkmark$ Procesar la información sin corromperla y trasformarla para que sea útil al usuario actual y al futuro y ofrecerla a tales usuarios para la satisfacción de sus respectivas necesidades, distribuyéndola de la forma mas conveniente posible. Por ejemplo, las universidades con las que nos relacionamos o los organismos de evaluación y acreditación que son nuevos usuarios que plantean y plantearan crecientes y diversificadas demandas.

$\checkmark \quad$ Almacenar los datos de forma que estén accesibles cuando se requieran y puedan transmitirse a organismos educativos de otras regiones y culturas.

Las cuestiones estratégicas en los sistemas de información educativos comprenden lo siguiente:

- Creación de una conciencia entre docentes, no docentes, profesionales y administradores educativos en cuanto al rol, las ventajas y las limitaciones de los sistemas de información y la tecnología relacionada.

- Definición y establecimiento de políticas y estrategias sobre la creación, introducción y funcionamiento de los sistemas de información educativos, incluidos los papeles o roles y las responsabilidades que ello conlleva.

- Identificación de inquietudes de sistemas de información educativos que deben considerarse en los planes de acción de programas, proyectos y unidades organizativas, en todos los niveles del sistema.

- Creación, apoyo y funcionamiento continuo de un área, grupo, equipo o comité asesor sobe sistemas de información de toda organización educativa que, por su tamaño y complejidad, lo requiera.

- Integración de todos los sistemas socio educativos existentes.

Las cuestiones estratégicas en la tecnología de información educativa comprenden lo siguiente:

- Definición de las características de los recursos tecnológicos que son más adecuados para satisfacer las exigencias de cada organización educativa, el ámbito organizacional existente y el futuro de la tecnología de información y 
las alternativas para el desarrollo de las aplicaciones. (Software para la gestión, redes, telecomunicaciones, desarrollo web, servicio técnico, etc.)

- Definición del equilibrio entre recursos técnicos centralizados y descentralizados para la prestación de servicios técnicos y para el desarrollo, la implementación y la operación de los sistemas.

- Definición de los lineamientos para la gestión de sistemas, incluidos el presupuesto, su distribución y el control de la función de información.

Las cuestiones tácticas de los sistemas y servicios de información educativa comprenden.

- Comprensión del papel cambiante de los sistemas de información y de sus componentes dentro de las organizaciones educativas y del impacto de los mismos en la estructura y en la gestión, capacitar para su uso y para aplicar diferentes metodologías de desarrollo, conforme la problemática y la planificación institucional

- Definición colaborativa por parte de los usuarios (rectores o presidentes, decanos, directores, responsables de unidades, de programas o proyectos, secretarios, funcionarios de alto nivel, etc.) de las actividades, programas, aplicaciones, etc. que requieren o revisten prioridad.

- Definición de alternativas para la implementación de sistemas, rutinas y procedimientos adecuados y la identificación del personal responsable del funcionamiento y mantenimiento de los sistemas.

Las cuestiones tácticas de la tecnología de información educativas incluyen las siguientes:

- Preparación de normas técnicas para la adquisición y despliegue del procesamiento de datos y de hardware y software de comunicación de datos. También para las funciones de administración y seguridad de datos y archivos e intervención de usuarios.

- Establecimiento de normas técnicas para el desarrollo de aplicaciones individuales, incluido el desarrollo interno, desarrollo por contrato, transferencia $\mathrm{y}$ adquisiciones directas, etc.

- Definición, al nivel de la aplicación, de las necesidades de capacitación de usuarios, rutinas operativas y procedimientos y seguridad relacionados con los datos para asegurar eficientemente su utilización. 
Los sistemas de información tradicionalmente han sido creados para una organización, un área de la misma o un tipo de actividades. Por lo tanto, su enunciación, diseño, implementación y evaluación se ha abordado desde una única perspectiva. Los nuevos requisitos al interior de las organizaciones educativas y entre las mismas de procesamiento de datos e información y comunicaciones causan muchas desviaciones de la situación original o anterior y obligan a adaptarse. Los sistemas de información interorganizacionales son sistemas mediante los cuales las entidades, organizaciones o unidades organizativas independientes (educativas, en nuestro caso) se comunicarán por transferencia de datos de la memoria de una computadora a otra. Se puede ver claramente que estos sistemas necesitan diferente gestión, desarrollo y prácticas en uso de las de los sistemas ordinarios intraorganizacionales.

Los puntos de diferencia parecen ser que los sistemas interorganizacionales

- No siempre pueden ser legitimados a corto plazo por los beneficios operativos estratégicos que producen; éstos llevan tiempo para que tengan lugar.

- No pueden basarse en sistemas actuales suficientes, bases de datos especiales, equipos de telecomunicaciones y normas

- Generan estrés en las actitudes cooperativas y de comunicaciones de los profesionales de sistemas, no siempre preparados adecuadamente.

- Requieren adecuación de los pareceres, conocimientos, habilidades y actitudes de los usuarios, tanto a nivel operativo como de conducción.

- Con frecuencia, necesitan acuerdos prioritarios en las fases iniciales; y

- Exigen una gran dedicación tanto en la calidad como en la intensidad del uso.

Los procesos de reforma educativa exigen una nueva orientación para los sistemas de información. Deben implementarse modelos descentralizados de la información y de los sistemas de información pero integrados, de conformidad con algunos de los argumentos vertidos y ante los cambios también explicados. Vistos los requerimientos de los procesos de convergencia, representan un punto de partida pero deben adaptarse o redefinirse por todo lo señalado anteriormente.

Tales procesos no pueden dejar de considerar estos aspectos:

- La evolución del contenido de valor de los sistemas de información y de la tecnología para las organizaciones educativas. 
- El impacto de la informática, la automatización y los sistemas de información en las organizaciones educativas sometidas a estos nuevos procesos: Mejora de la calidad, reorganización interna, evaluación institucional, acreditación de carreras, convergencia de estudios, títulos, etc.

- El cambio organizacional aplicado en ámbitos educativos de cada país y región

- Las recomendaciones de organismos supranacionales respecto de la internacionalización de la educación

- La instalación de estos nuevos sistemas y enfoques y su repercusión en docentes, no docentes, alumnos, graduados, funcionarios, etc.

En suma, la importancia creciente de los sistemas de información educativos para

- Evaluar el contexto y anticipar fenómenos sociales

- Atender necesidades diferenciales de los actores relevantes de las organizaciones educativas

- Realizar acciones de seguimiento y evaluación

- Contrastar entre instituciones y articular mejor

- Incrementar la eficiencia en el uso de los recursos

- Contribuir a medir calidad, equidad, pertinencia, etc.

En síntesis, para mejorar la calidad de toda la institución a partir de la mejora de su administración y gestión y de los sistemas de información de los cuales se vale.

Ahora bien, los problemas de los sistemas de información educativos no sólo son responsabilidad de los técnicos; no pueden ser abordados por especialistas ni por profesores ni por filósofos. Es responsabilidad de todos.

\section{V}

El mayor obstáculo es el modelo mental de los administradores educacionales (presidentes o rectores, decanos, directores de escuelas, de departamentos y otras áreas, miembros de los consejos superiores y académicos, secretarios) y las presiones del sistema que impiden comprender que la situación es profundamente dinámica por su naturaleza $\mathrm{y}$, como dicen los teóricos de los sistemas abiertos, que el equilibrio no es sino un continuo proceso de cambio. La visión 
estática no sirve; cambia, busca un nuevo equilibrio y, en el mismo y con nuevas restricciones, se congela. El modelo mental centrado en el crecimiento y desarrollo organizacional y de sus miembros permite entender mejor el cambio en el entorno y sus efectos sobre la educación y la estructura, enfrentarlos y adoptar las decisiones acertadas, logrando el crecimiento del conjunto que es la universidad o la organización educativa de que se trate.

Un administrador educacional debe ser un técnico y un líder, al mismo tiempo, y cumplir funciones económicas, humanas e integradoras en el proceso de conducción. Si queremos que administre correctamente y para el desarrollo de sus capacidades estratégica, interpersonal, emocional -para asumir riesgos e internacionalizar problemas- y técnicas o de gestión específica, no sólo debemos capacitarlo en sus competencias, en el ejercicio de la autoridad, en la generación de confianza en sus decisiones y en la recreación de aspectos éticos y morales sino proveerlo de sistemas de información adecuados.

Un nuevo modelo de administrar la educación debe insertarse en una verdadera política de conocimiento. Es tan importante dominar los sistemas de información para un administrador educacional como tener formación pedagógica para un docente. Administrar una universidad o una escuela no es una cuestión menor a la que se llega por cuestiones ajenas a la capacitación específica; muchas de ellas, son las más desorganizadas y se desconoce el hecho de que los problemas de gestión tienen identidad propia y como tal deber ser tratados. Creo que ha quedado claro que los sistemas de información son cruciales en este sentido.

Las organizaciones educativas y aún más, las universidades representan una forma especial de poder. Muchos de los que las dirigen son representantes del poder de turno y no verdaderos y ecuánimes administradores educacionales. Si la información otorga poder, démoselas porque son los responsables institucionales hacia la comunidad y demás involucrados y hagámoslos responsables efectivos de sus decisiones.

Con relación a la información y sus sistemas, los nuevos administradores educacionales en las universidades (y, seguramente con algunas variaciones, en otras organizaciones) deben:

- Aprender a operar en un mercado global de la información y la tecnología y en distintos escenarios y a interpretar la información de distintas formas.

- Aprender a hacer de la información interna y externa y de un equilibrio entre ambas una verdadera herramienta de trabajo. 
- Aprender a preguntar: ¿Qué datos preciso para mi trabajo?, ¿Cómo, cuándo, a quién, dónde puedo encontrarlos, dónde aplicarlos y para qué?

- Aprender a administrar basado en la información redefiniendo sus contenidos junto con la responsabilidad gerencial o directiva sobre ella, recordando que existe un manejo indirecto: no vemos los hechos sino la información de referencia

- Incrementar el manejo habitual de información cualitativa, transformándola en cuantitativa, a pesar de las dificultades de interrelación.

- Incrementar el conocimiento sobre el avance de las tecnologías que no son propias del rubro específico pero que puede beneficiar su trabajo.

- Aprender a redefinir la responsabilidad del proveedor de información y del especialista en informática

- Desterrar la ilusión de tener información por tener gran capacidad para procesar datos, optimizando el con qué: software y hardware.

- Capacitar y capacitarse para usar la información, para delegar lo que corresponda y para pilotear transformaciones educativas

- Vincular los distintos tipos de información e integrarlas en un modelo compartido

- Aprender a transformar a la información y a sus sistemas en un exigente y delicado mecanismo de planificación, ejecución, gestión y evaluación; un verdadero tablero de comando, combinando permanencia y continuidad con innovación y cambio, con visión positiva del futuro y coherencia para guiar el accionar.

Con mejor información, habrá mejores decisiones para:

- No despilfarrar recursos y lograr objetivos con transparencia, eficiencia, eficacia, efectividad y relevancia

- Solucionar cuestiones estructurales (Superposición de funciones en niveles centrales y desconcentrados, inadecuada distribución de las mismas, problemas en áreas de Investigación, Extensión, Transferencia, Becas, Pasantías, Centros Regionales, Bienestar estudiantil, Relaciones institucionales, etc.)

- Discutir y transmitir los fines, la misión y los objetivos y metas del período

- Evitar la fragmentación estructural o una federación de facultades

- Evitar el aislamiento de la gestión y de las cátedras y otras unidades operativas 
- Unir planes de naturaleza estratégica con la programación detallada, resolviendo problemas de ingreso, entre otros.

- Mejorar a todos los miembros

- Autoevaluarse, corregir e incrementar la calidad

- Mejorar las relaciones con el ambiente externo

- Superar tensiones y conflictos; v.g., entre lo académico y profesional, entre los departamentos, entre el grado y el postgrado, entre planes institucionales y departamentales, etc.

- Equilibrar las funciones de docencia, investigación, extensión y transferencia

- Integrarse con otras instituciones educativas del país, la región y el mundo, resolviendo la mayor parte de los inconvenientes en los procesos de convergencia educativa

Para ello, entre otras cuestiones, ahora vinculadas a su capacidad de conducción, debe aprender a trabajar con colegas, sin soberbias, a rodearse de los mas capaces sin temor, a liderar y demandar liderazgo, a optimizar los recursos humanos sin nepotismo ni favoritismo, a capacitar y capacitarse en forma permanente, a incrementar la responsabilidad propia y de su equipo, a planificar, reestructurar y evaluar sistemática y objetivamente, a redefinir al rebelde innovador, al genio sabelotodo y al burócrata conservador, a reconocer la cultura de su organización y de las que se vincule y a equilibrar necesidades políticas, institucionales, propias y las de su personal.

La información y los sistemas de información que utilicemos deben permitirnos indagar y conocer para intervenir. La intervención y los análisis deben realizarse desde marcos conceptuales específicos a conocer, tomando posición frente a ellos. Tanto los modelos científico racional, interpretativos simbólicos o crítico sociales como los de gestión universitaria (germano, napoleónico, simil administración pública, estadounidense o del management) deben ser discutidos porque los resultados de la gestión se evalúan distinto desde distintas posiciones.

Las universidades son las organizaciones educativas más importantes para todos estos desafíos. La universidad requiere un nuevo sistema de vigencias, debemos fecundar en ella para mejorarla a si misma y a los demás niveles del sistema educativo. También las asociaciones de profesores y de graduados en todas las disciplinas y profesiones. Muchas veces, el corporativismo perjudica 
y mucho; se requiere sincerarse acerca del valor de los sistemas de información y de la tecnología informática y de la formación necesaria para su uso. Hay, necesariamente, que mejorar e integrar para que la educación cumpla con su deber; compromiso insoslayable para todo miembro del sistema educativo.

Organismos como la UNESCO plantean la necesidad de incrementar la pertinencia de las actividades educativas de docencia, investigación, extensión, difusión y servicio a la comunidad y para esto recomiendan una efectiva y adecuada integración. Los sistemas de información son medios eficaces para ello. El desarrollo y una mejor integración de las funciones aludidas obligan a una reorganización de las Instituciones de Educación Superior. Reitero que es necesario repensar y poner en práctica políticas y acciones de cooperación múltiples.

La Investigación describe y/o explica la realidad desde la rigurosidad metodológica, descubre regularidades que sustentan la construcción de teorías y es soporte del proceso de enseñanza aprendizaje, que impacta sobre la realidad sólo si se la puede incorporar al proceso nuevamente. La Extensión es el puente entre la investigación y la docencia; agrega valor, siempre. La Docencia, al intentar formar plenamente a los sujetos que se educan, se nutre de ambas. Todos los servicios de apoyo y los sistemas de información deben compadecerse de ello.

En los hechos, la integración a la que se hace referencia en el párrafo anterior no es sencilla. Se requiere una actitud más competente hacia el compromiso social y la calidad. Existen y existirán problemas para integrar las funciones citadas y compartir la información en forma efectiva. Los mas difíciles de solucionar, además de lo expuesto antes, son la cultura, las costumbres y las estrategias y prácticas tradicionales de las instituciones educativas que favorecen los compartimentos estancos y la separación. Otras restricciones obedecen a la complejidad de la estructura, a liderazgo personalísimos, a los actuales sistemas de información educativos que no parecen suficientes para mejorar procesos decisorios, a los problemas y ruidos comunicacionales que debemos evitar, a los perfiles de cada institución y a sus carreras que suelen dificultar el acercamiento y a las distintas experiencias sobre procesos de cambio organizacionales y de adaptación al entorno.

Los sistemas de información deben acompañar un nuevo modelo de integración de las funciones de docencia, extensión e investigación que resultará de los cambios en el modelo y modalidades de gestión. Seguramente, aparecerán debates en cuestiones político estratégicas, con referencia al marco decisorio y a los eternos problemas de la centralización y descentralización y la distri- 
bución de los recursos. Pero, los cambios siguen a la estrategia. Seguramente, en los próximos tiempos y como respuesta a los procesos de evaluación y acreditación, se diseñarán nuevas estratégicas y aparecerán, obviamente, problemáticas específicas a las que no se les ha prestado suficiente atención aún y cuyos obstáculos habrá que superar mediante el compromiso, la inteligencia y la capacidad de adaptación de todos los actores responsables para encauzar la transformación.

En términos propios de la disciplina a la que pertenezco, los expertos recomiendan pasar de "una burocracia profesional a una entidad orgánica y revisar el modelo de gestión existente a partir del conocimiento y la información adecuada". Acostumbrada a enseñar o a ayudar a aprender a los demás, la Universidad tendrá que aprender ella y sus miembros en la medida que la sociedad lo espera. Para satisfacer mejor las necesidades que plantean los nuevos desafíos en docencia e investigación y los provenientes de la comunidad y para mejorar su imagen, la Universidad deberá implementar actividades que favorezcan el aprendizaje y la creatividad de todos los miembros y equipos, elevándose a un plano de mejora continua con un cambio proactivo, con buenos y adecuados sistemas de información y la gestión del conocimiento como forma de vida implícita en las decisiones de los que administran, gobiernan, gestionan, etc.

Yo aguardo esperanzas ciertas que todos ayudaremos para que la Universidad sea capaz, en la actual sociedad del conocimiento con un avance científico y tecnológico sin precedentes, de transformarse en una organización que aprende con un desarrollo basado en las personas y equipos integrando el pensar, el ser, el estimar, el valorar y el hacer, considerando las interacciones con el entorno y la influencia recíproca y transformando sus sistemas de información en verdaderos sistemas de apoyo decisional, comunicación e influencia.

En síntesis, una Universidad capaz de tejer permanentemente la habilidad de cambiar y adaptar la esencia de su carácter con valores, hábitos, políticas, programas, sistemas, procesos y estructuras que apoyen y aceleren el aprendizaje organizacional para todos y con todos. En tal entendimiento, los sistemas de información representan un desafío constante y permanente.

Es muy difícil resolver problemas sólo, la integración aludida es insoslayable. El compartir nos nutrirá y serviremos mejor a los demás. Todos los miembros de la Universidad debemos creer y querer lo que hacemos y tener posibilidades de crear, recrear y auto realizarnos en nuestro trabajo. Como decía mi padre que no fue a la universidad: "Quién no es feliz en su trabajo no es feliz mientras vive" y, como decían los antiguos, "la ciencia y el conocimiento son el bien"; pues entonces, hagámoslo con todos y para todos. 
Bibliografía general sobre sistemas de información y sobre aplicaciones en el ámbito público:

BARCOS, Santiago José, con la colaboración de los profesores Elena Denda, Norma Paolini, Diego Álvarez Gelves y Nicolás Di Giovan Battista: Aprendiendo el proceso administrativo y algo más. La Plata, Editorial Dei Genitrix, La Plata, 2006.

DEL POZO NAVARRO, M.: La dirección por sistemas. México: Editorial Limusa, 1979.

EMERY, J. Sistemas de Planeamiento y Control de la Empresa. Buenos Aires: Editorial El Ateneo, 1987.

FEIJÓO, R. ¿Qué es un buen sistema de información? Revista Administración de Empresas, Buenos Aires, Tomo VI-B, Páginas 945 a 955, Octubre 1975/Marzo 1976, Ediciones Contabilidad Moderna.

Dirección Provincial de Rentas del Ministerio de Economía de la Provincia de Buenos Aires: Material didáctico preparado por el Área de Desarrollo de Recursos Humanos y utilizado en cursos de formación gerencial en el ámbito público referido a sistemas de información de organizaciones tributarias, de salud, educativas, etc., La Plata, 1992.

LAUDON, K. C. y LAUDON, J. P. Administración de los Sistemas de Información. México, Prentice Hall Internacional, 2002.

LOSOVIZ, P. Sistemas de Información. Revista Administración de Empresas, Buenos Aires, Tomo VI-A, páginas 501 a 528, Abril a septiembre de 1975, Ediciones Contabilidad Moderna.

MAGDALENA, F. Sistemas administrativos. Buenos Aires: Grupo Editor Macchi, 1999.

MONFORTE, M. Sistemas de Información para la Dirección. Madrid, Ed. Pirámide, 1995.

SAROKA, R. H. Sistemas de información en la Era Digital: mimeo. La Plata: FCE-UNLP, 2002.

SENN, J. A. Análisis y diseño de sistemas de información. México: Editorial Mc Graw Hill, 1992. 


\section{Referencias}

ARISMENDI POSADA, Octavio. Problemas de la administración educativa en América Latina. La Plata: FHyCE-UNLP, 1995.

AZZERBONI, Delia; HARF, Ruth. Conduciendo la escuela: manual de gestión directiva y evaluación institucional. Buenos Aires: Ediciones Novedades Educativas, 2003.

BARCOS, S.J.; ASPRELLA, G. Material didáctico de la cátedra de Administración de la Educación y de las Instituciones Educativas, Facultad de Humanidades y Ciencias de la Educación de la UNLP, La Plata, 2004.

Comisión Nacional de Evaluación y Acreditación Universitaria de Argentina CONEAU. Informes sobre evaluaciones externas. Buenos Aires, 1997/2006.

DOMÍNGUEZ FERNÁNDEZ, G. y MESANZA LÓPEZ, J. (Compiladores.). Manual de organización de instituciones educativas. Madrid, Editorial Escuela Española, 1996.

FÉLIX ANGULO, J. Calidad educativa, calidad docente y de gestión. Madrid, Ed. Aljibe, 1996.

FERNÁNDEZ LAMARRA, Norberto. Cuadros resúmenes. Reflexiones sobre la educación y la escuela necesaria. Ciclo: De la escuela actual a la escuela necesaria, Buenos Aires: UNTREF, 2005.

FERNÁNDEZ LAMARRA, Norberto. La construcción del espacio común latinoamericano de educación superior y su convergencia con el europeo. El rol de las universidades. La Plata: Universidad Nacional de La Plata, junio de 2006. Conferencia.

FERNÁNDEZ LAMARRA, Norberto. Educación superior y calidad en América Latina y Argentina. Buenos Aires: IESALC - EUNTREF, 2007.

FERNÁNDEZ LAMARRA, Norberto. Veinte años de educación en la Argentina: Balance y perspectivas. Buenos Aires, EDUNTREF, 2002.

FERNÁNDEZ LAMARRA, Norberto; ALONSO BRÁ, Mariana. La gestión universitaria en la Argentina: Una aproximación a partir de la evaluación institucional externa. En: COLOSSI, Nelson; DÍAS DE SOUZA PINTO, Marli. Estudos e Perspectivas en Gestäo Universitaria. Blumenau, SC: Nova Letra, INPEAU-UFSC, 2004. 
GINÉS MORA, José; FERNÁNDEZ LAMARRA, Norberto. (Coordinadores.). Educación superior: convergencia entre América Latina y Europa - Procesos de Evaluación y Acreditación de la calidad, Buenos Aires: Editorial de la Universidad Nacional de Tres de Febrero, EDUNTREF, 2005.

HALLÚ, Rubén: Declaraciones realizadas en su carácter de del rector de la Universidad de Buenos Aires, transmitidas en emisiones televisivas del día 13 de febrero de 2007 y publicadas, previa adaptación, en los periódicos argentinos al día siguiente.

KNIGHT, Jane. Nuevos desarrollos en educación superior en América Latina, opiniones y tendencias: Encuesta 2005/6. Reporte Integral - Proyecto 6x4 UEALC. Canadá: University of Toronto, Sep. 2006.

MARTÍNEZ NOGUEIRA, Roberto; GÓNGORA, Norberto. Evaluación de la gestión universitaria - Informe para la CONEAU, Argentina, 2000 .

PALLÁN FIGUEROA, Carlos. Calidad, evaluación y acreditación en México. En: Ttrabajo presentado en el Workshop Internacional: O Papel do CRUB na avaliacao, 1999. Río de Janeiro. Trabalho apresentado Consejo de Rectores de las Universidades Brasileñas, mayo, 1999.

PANIZZI, Wrana María. La universidad desafiada - versión preliminar. Universidade Federal do Río Grande do Sul, Brasil. En: Universidad Nacional de Cuyo, Proyecto 6X4, Mendoza, Argentina, UEALC, oct., 2006.

SANTOS GUERRA, M. A.: Entre Bastidores, el lado oculto de la organización escolar. Málaga, España, Ediciones Aljibe, 1994.

Tercer SEMINARIO INTERNACIONAL DE SEGUIMIENTO DEL PROYECTO 6X4 UEALC. Seis profesiones en cuatro ejes: Un diálogo universitario, 3, 2006, Mendoza, Argentina, Material ad-hoc.

VALES, Alicia: La construcción de un sistema de información socio educativo. REPLAD-OREALC, Buenos Aires, Facultad de Filosofía y Letras de la Universidad de Buenos Aires, 1994 y sucesivas reimpresiones. 